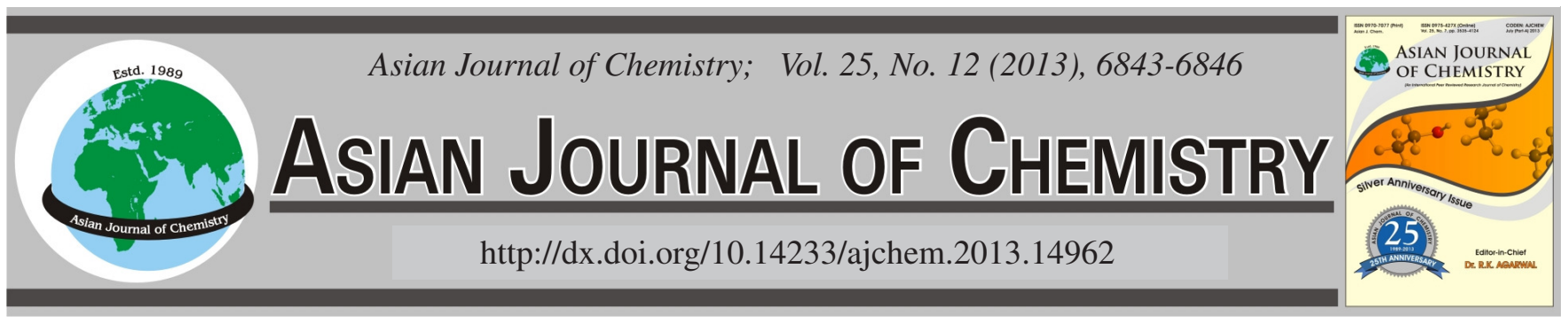

\title{
Visible Near-Infrared Reflectance Spectroscopy Determination of Some Chemical Characteristics of Different Particular Sizes in Soils
}

\author{
H. Senol ${ }^{*}$, M. Akgul, M. Mujdeci and L. Basayigit
}

Department of Soil Science and Plant Nutrition, Faculty of Agriculture, Suleyman Demirel University, Isparta, Turkey

*Corresponding author: Fax: +90 246 2118696; Tel: +90 246 2118607; E-mail: huseyinsenol@ sdu.edu.tr

The main objective of this study is to evaluate the ability of visible near-infrared reflectance spectroscopy (VNIRS) to predict diverse soil
chemical properties in grinding different particular size effect. In this study, 60 soil samples were collected from the fields with serial
classification (entisols, inceptisols, vertisols and mollisols) in Isparta (Atabey) district and crushed samples were subjected into five
different mesh sizes ( $4.76-2.00,2.00-1.00,1.00-0.50,0.5-0.25$ and $<0.25 \mathrm{~mm}$, respectively). Each soil samples were scanned with a
visible near-infrared spectrometer, with a spectral range of 350 to $2500 \mathrm{~nm}$, at five different particular sizes. The spectral reflectance's
were used to predict some chemical properties of the soil (lime, sum of organic matter, cation exchange capacity, exchangeable calcium
+ magnesium, exchangeable potassium, exchangeable sodium) using partial least squares regression. Partial least squares analysis was
used to develop calibration models between smoothed-first derivative $6 \mathrm{~nm}$ spaced spectral reflectance data and soil chemical analysis
measured lime, sum of organic matter, cation exchange capacity, exchangeable calcium + magnesium, exchangeable potassium,
exchangeable sodium. The results showed that while soils need to be crushed to pass through 0.25 mm sieve in order to determine
exchangeable calcium + magnesium, exchangeable sodium, mesh size was found non-significant in determining lime, sum of organic
matter, cation exchange capacity, exchangeable potassium and the results obtained from the reflectance values taken from field samplings
proved to be satisfactory.

Key Words: Visible near-infrared reflectance spectroscopy, Particle size, Lime, Cation exchange capacity, Sum of organic matter.

\section{INTRODUCTION}

Remote sensing is an important tool in agriculture and soil evaluation, contributing to the collection novel information as a non-destructive, quick and low-cost technique ${ }^{1}$.

Many conventional soil analytical techniques are used in an attempt to establish the relationship between soil physical and chemical properties and individual soil components, often disregarding their complex, multi-component interactions ${ }^{2}$.

Standard procedures for measuring soil properties being time-consuming and expensive, much attention is given to possible alternatives such as near infrared reflectance spectroscopy (NIRS). Near infrared reflectance spectroscopy is a non-destructive analytical technique for studying interactions between incident light and a material's surface ${ }^{3}$. Near infrared reflectance spectroscopy is a physical non-destructive, rapid, reproducible and low-cost method that characterizes materials according to their reflectance in the wavelength range between 350 and $2500 \mathrm{~nm}^{2,4-7}$.

Infrared spectroscopy in the near and mid-infrared ranges has been found to be useful in providing rapid, cheap and relatively accurate predictions for a number of soil properties ${ }^{2,4-7}$.
Many studies have focused on measuring soil properties using NIRS $S^{2-4,8,9}$. These studies proved that soil chemical properties can be predicted well or satisfactorily by NIRS. However, reflectance spectra are strongly affected by the contents of soil moisture, organic matter and iron, texture, structure and particle size. The effect of MC on soil spectra was highlighted by Mouazen et al. ${ }^{10}$, without quantifying this effect on the prediction of other soil properties. Chang et al. ${ }^{3}$ used $8 \mathrm{~mm}$ sieve with sifted 802 soils samples by using NIRS scatterings. The authors concluded that cation-exchange capacity (CEC), was successfully predicted by NIRS $\left(R^{2}>0.80\right)$. A NIR soil sensor in surface and subsurface soils was used for predict of soil organic matter contents by Hummel et al. ${ }^{11}$. Standard errors of prediction for organic matter were 0.62 . While it was suggested by Fystro $^{12}$ that grinding the samples did not improve the prediction accuracy, Dalal and Henry ${ }^{13}$, Reeves et al. ${ }^{14}$ and Russell ${ }^{15}$ pointed out that particle size of soils plays a significant role in organic carbon contents.

The accurate sensing and determination of characteristics concentration in soil samples using spectral measurements are dependent upon the condition of soil sample, instrument and 
environment. The condition of soil sample includes soil type, particle size and moisture content. The reflectance spectra of the soil samples are influenced by soil particle size and structure. Elimination of these effects requires a calibration model to remove the effects of soil particle size and structure. The effectiveness of iron and organic matter on the reflection measurements can be eliminated using different methods. But the effects of soil structure on the reflections are not considered. Therefore, this study is aimed to evaluate the ability of visible near-infrared reflectance spectroscopy (VNIRS) to predict diverse soil chemical properties in grinding different particular size effect.

\section{EXPERIMENTAL}

Field sites and sampling: The fields were located in Isparta Atabey district (37 $52^{\prime} 30^{\prime \prime} \mathrm{N}$; 30 $\left.00^{\prime} 00^{\prime \prime} \mathrm{E}\right)$ in Turkey. In Isparta, the mean annual temperature is $12.4^{\circ} \mathrm{C}$ with monthly means between $1.6^{\circ} \mathrm{C}$ January and $23.8^{\circ} \mathrm{C}$ July and annual rainfall $524 \mathrm{~mm}$, three-fourth occurring during the warm season (June to September $)^{16}$. The soil was entisol, inceptisol, mollisol and vertisol according to the USDA soil taxonomy ${ }^{16,17}$.

Sixty $(n=60)$ soil samples were collected from Atabey district in 2008. The soils were sampled at surface $(0-30 \mathrm{~cm})$. Before scanning, samples were air-dried and crushed. The samples were graded into five particle sizes (4.76-2.00, 2.00$1.00,1.00-0.50,0.50-0.25,<0.25 \mathrm{~mm}$ diameter, respectively) using sieves.

Soil samples were oven dried at $40^{\circ} \mathrm{C}$, ground and sieved to obtain the $<2 \mathrm{~mm}$ fraction. The calcimeter method (lime) $)^{18,19}$ was used to measure the carbonate concentration in the soil. Organic matter (SOM) was determined by a modification of the Walkley and Black's titration method as outlined by Nelson and Sommers ${ }^{19}$. Cation exchange capacity (CEC) was determined with $1 \mathrm{~N} \mathrm{Na-acetate}$ at $\mathrm{pH} 8.2$ exchangeable bases were extracted with $1 \mathrm{~N} \mathrm{NH}$ acetate at $\mathrm{pH} 7.0$ and measured by atomic absorption spectroscopy $\mathrm{Na}$ and $\mathrm{K}$. Exchangeable $\mathrm{Mg}$ and exchangeable $\mathrm{Ca}$, cation exchange capacity were determined by subtracting the exchangeable $\mathrm{Na}$ and $\mathrm{K}$ cation ${ }^{20,21}$.

Near-infrared reflectance spectroscopy scanning and data analysis: The soil samples were scanned using an ASD FieldSpec Pro FR VNIR spectroradiometer with a spectral range of 350 to $2500 \mathrm{~nm}, 1 \mathrm{~nm}$ sampling resolution. The spectroradiometer was equipped with a contact probe. The contact probe has a viewing area defined by a $2 \mathrm{~cm}$ diameter circle and its own light source. A spectralon panel with $99 \%$ reflectance was used to optimize the spectrometer each day. The same panel was used as a white reference before scanning each sample. The air-dried surface soils were scanned from below with an ASD mug lamp connected to the FieldSpec Pro FR. A spectralon $99 \%$ reflectance panel was used to optimize. Approximately $20 \mathrm{~g}$ of surface soil was placed into a Duraplan borosilicate optical-glass Petri dish. Each sample was scanned three times with a $90^{\circ}$ rotation between scans.

Reflectance spectra of different particular size soil samples were measured in UV, VIS and NIR regions between 350 and $2500 \mathrm{~nm}$ with a sampling interval of $1 \mathrm{~nm}$. The initial spectral data ranged from 350 to $2500 \mathrm{~nm}$, but because of low signalto-noise ratios at the ends of the spectra, only data in the 400 to $2440 \mathrm{~nm}$ range ( $6 \mathrm{~nm}$ spacing-341 data points) were included in the analyses. The spectral reflectance data were normalized by dividing each reflectance value by the mean reflectance of the 341 bands within each spectrum, creating a second data set with a mean of 1 . These data were also transformed to normalization. Then, the first derivative of spectra is computed to reveal information hidden in the spectra and also to reduce baseline drift. Smoothing the optical signal with derivative filters (Savistky-Golay) can help to lessen spectral noise as well as scattering corrections like multiplicative scatter correction (MSC) or standard normal variety (SNV) correction. After pretreatment, statistical tools relevant to the aim of the analysis were implemented to analyze spectral data. Calibration development and soil property estimation were accomplished with partial least squares regression (PLS) techniques implemented in the PC-based Unscrambler software 9.7 (CAMO A/S, Trondheim, Norway). Correlations of the normalized soil spectra and physical property data were accomplished using step-wise multiple linear regressions for the overall dataset.

Near-infrared reflectance spectroscopy prediction for soil properties: The size, shape and arrangement of particles in a sample can affect the path of light transmission and the reflectance spectra, as such NIR spectra are assumed to exhibit a primary response to soil texture and structure. Soil particlesize distribution and macroaggregation exhibited a unique spectral response to incident light ${ }^{22}$.

Instruments operating in the NIR region (700-2500 nm) must be calibrated before they can be used. Because of the complex nature of NIR spectral data, the instrument must be calibrated on a series of natural samples representative of the population to be measured. The calibration was performed using partial least square. Multivariate algorithms are often used to compress the dimension of the problem and to reduce multicollinearity in NIR data. Spectra are normally preprocessed before calibration to remove or reduce effects not related to the chemical absorption of light. Often used treatments are multiplicative scatter correction, standard normal variety transformation, standard normal variety transformation combined with Detrend and first or second derivatives ${ }^{23}$. In this study, the results indicate that the first derivative spectra provide more effective information for selecting similar samples.

\section{RESULTS AND DISCUSSION}

Soil properties: The percentage of lime in the samples ranged from 0.20 to $25.40 \%$ (Table-1). Values for sum of organic matter were between 0.94 and $2.40 \%$, cation exchange capacity (CEC), exchangeable $\mathrm{Ca}+\mathrm{Mg}$, exchangeable $\mathrm{K}$ and exchangeable Na, 7.20-36.25, 6.60-35.05, 0.23-1.85, 0.50-1.52 (me/100g) concentrations in the range, respectively.

Prediction of soil chemical properties: According to PLS analysis results to estimate the lime contents, the high $\mathrm{R}^{2}$ value was found to be 0.84 in validation $(\mathrm{RMSE}=2.95$ ) for soil set of the $0.250 \mathrm{~mm}$ sieve. But in all sieve groups, obtaining $\mathrm{R}^{2}$ value between $0.81-0.84$ in all mesh sizes revealed that sieve size was not significant in determining lime (Table-2). In the NIR the average $R^{2}$ value for prediction of soil lime has been reported to be $0.69^{24}$, in the middle infrared reflectance spec- 
TABLE-2

VALIDATION STATISTICS FOR THE CROSS-VALIDATED PREDICTIONS OF VARIOUS SOIL PROPERTIES USING PLS

\begin{tabular}{|c|c|c|c|c|c|c|c|c|c|c|c|c|}
\hline \multirow{2}{*}{$\begin{array}{l}\text { Sieve } \\
(\mathrm{mm})\end{array}$} & \multicolumn{2}{|c|}{ Lime } & \multicolumn{2}{|c|}{ SOM } & \multicolumn{2}{|c|}{ CEC } & \multicolumn{2}{|c|}{ Exc. $\mathrm{Ca}+\mathrm{Mg}$} & \multicolumn{2}{|c|}{ Exc. K } & \multicolumn{2}{|c|}{ Exc. Na } \\
\hline & $\mathrm{RMSE}^{\mathrm{a}}$ & $\mathrm{R}^{2}(\mathrm{v})^{\mathrm{b}}$ & RMSE & $\mathrm{R}^{2}(\mathrm{v})$ & RMSE & $\mathrm{R}^{2}(\mathrm{v})$ & RMSE & $\mathrm{R}^{2}(\mathrm{v})$ & RMSE & $\mathrm{R}^{2}(\mathrm{v})$ & RMSE & $\mathrm{R}^{2}(\mathrm{v})$ \\
\hline 0.250 & 2.95 & 0.84 & 0.07 & 0.98 & 2.97 & 0.84 & 4.01 & 0.69 & 0.33 & 0.35 & 0.07 & 0.91 \\
\hline 0.500 & 2.95 & 0.84 & 0.32 & 0.55 & 2.96 & 0.84 & 2.93 & 0.83 & 0.33 & 0.37 & 0.11 & 0.74 \\
\hline 1.000 & 3.19 & 0.81 & 0.33 & 0.52 & 3.04 & 0.83 & 2.98 & 0.83 & 0.31 & 0.42 & 0.13 & 0.67 \\
\hline 2.000 & 3.13 & 0.82 & 0.31 & 0.56 & 3.30 & 0.80 & 3.23 & 0.80 & 0.32 & 0.39 & 0.12 & 0.70 \\
\hline 4.760 & 3.15 & 0.81 & 0.33 & 0.51 & 2.31 & 0.90 & 2.29 & 0.90 & 0.29 & 0.51 & 0.07 & 0.89 \\
\hline
\end{tabular}

\begin{tabular}{lccc}
\multicolumn{4}{c}{ TABLE-1 } \\
\multicolumn{4}{c}{ LABORATORY RESULTS FROM } \\
CHEMICAL ANALYSIS \\
\hline \multicolumn{1}{c}{ Parameter } & Mean & Range & SE $^{\mathrm{d}}$ \\
\hline Lime $(\%)$ & $7.92(7.33)^{\mathrm{e}}$ & $0.20-25.40$ & 0.95 \\
$\mathrm{SOM}^{\mathrm{a}}(\%)$ & $1.69(0.47)$ & $0.94-2.40$ & 0.06 \\
$\mathrm{CEC}^{\mathrm{b}}(\mathrm{meq} / 100 \mathrm{~g})$ & $18.61(7.43)$ & $7.20-36.25$ & 0.96 \\
$\mathrm{Exc}^{\mathrm{c}} . \mathrm{Ca}+\mathrm{Mg}(\mathrm{meq} / 100 \mathrm{~g})$ & $17.49(7.22)$ & $6.60-35.05$ & 0.93 \\
Exc. K $(\mathrm{meq} / 100 \mathrm{~g})$ & $0.98(0.42)$ & $0.23-1.85$ & 0.05 \\
Exc. $\mathrm{Na}(\mathrm{meq} / 100 \mathrm{~g})$ & $0.85(0.22)$ & $0.50-1.52$ & 0.03 \\
\hline
\end{tabular}

${ }^{\mathrm{a}} \mathrm{Sum}$ of organic matter; ${ }^{\mathrm{b}}$ Cation exchangable capacity; ${ }^{\mathrm{c}}$ Exchangable; ${ }^{\mathrm{d}}$ Standard error; ${ }^{\mathrm{e}}$ Parentheses: indicate standard deviation.

troscopy (MIR) $0.95^{25}$. Results showed that the reflectance values obtained from field samples or sieved samples (mesh size $4.76 \mathrm{~mm}$ ) can be used to estimated lime contents.

Partial least squares analysis according to SOM, the best estimate in the soil set of the $4.76 \mathrm{~mm}$ sieve was found as $\mathrm{R}^{2}=$ 0.90 in validation $(\mathrm{RMSE}=2.29)$. However, all sieve groups outside in $0.250 \mathrm{~mm}$ sieve the soil samples of the reflection with the highest values $(0.83-0.80)$ were obtained validation. Therefore, the overall size (except for $0.250 \mathrm{~mm}$ ) to obtain sieve size is important in determining SOM. Similarly, Daniel et al. ${ }^{26}$ laboratory calibrations of soil reflectance data collected with NIR spectroscopy (400-1100 nm) yielded an $\mathrm{R}^{2}$ of 0.86 for 41 soil samples. But, in the NIR region by multiple regression analysis $(1000-2500 \mathrm{~nm})$ the average $R^{2}$ value for prediction of soil organic matter has been reported to be $0.55^{24}$, in the VIS-NIR by stepwise multiple linear regression (400$2400 \mathrm{~nm}) 0.65$.

Several soil properties that do not have a primary response in the near-infrared region, such as CEC and exchangeable cations, were accurately predicted by the NIRS-PCR. Correlation of these properties with soil organic matter and clay content may explain some of this effect ${ }^{3}$. According to PLS analysis results to estimate the CEC, the high $\mathrm{R}^{2}$ value was found to be 0.51 in validation $(\mathrm{RMSE}=0.29)$. But in all sieve groups, obtaining $\mathrm{R}^{2}$ value between $0.37-0.51$ in all mesh sizes revealed that crushing degree was not significant in determining CEC (Table-2). In the NIR the average $\mathrm{R}^{2}$ value for prediction of soil CEC has been reported to be $0.81^{3}$. Chang et al. $^{27}$, before NIRS scattering, samples through a $2 \mathrm{~mm}$ sieve. Authors indicated that NIRS-PLSR was able to predict CEC with reasonable accuracy for both the air-dried $\left(R^{2}>0.76\right)$ and moist $\left(\mathrm{R}^{2}>0.74\right)$ soils. Other authors indicated that different spectral region (MIR, NIR, VIS-NIR and UV-VIS-NIR) and different multivariate methods (PLSR, MRA, PCR and MARS) were able to average $\mathrm{R}^{2}$ value for prediction of soil CEC has been reported to be $0.88,0.67,0.88,0.64^{5,28,29,28}$, respectively.
Cation exchange capacity of the exchangeable cations as well as indirectly determined by near infrared reflectance spectroscopy. According to PLS analysis results to estimate the exchangable $\mathrm{Ca}+\mathrm{Mg}$, exchangable $\mathrm{K}$ and exchangable $\mathrm{Na}$ the high $\mathrm{R}^{2}$ value was found to be $0.91,0.84$ and 0.98 , respectively in validation (RMSE $=0.07,2.95,0.07$, respectively) for soil set of the $0.250 \mathrm{~mm}$ sieve. But in all sieve groups, obtaining $\mathrm{R}^{2}$ value between 0.91 and 0.89 in 0.250 or 4.76 mesh sizes revealed that sieve size was significant in determining exchangable $\mathrm{Ca}+\mathrm{Mg}$ (Table-2). To exchangable $\mathrm{K}$, results showed that the reflectance values obtained from field samples or sieved samples (mesh size $4.76 \mathrm{~mm}$ ) can be used to estimate. Obtaining $\mathrm{R}^{2}$ value between $0.81-0.84$ in all mesh sizes revealed that sieve size was not significant in determining exchangable $\mathrm{K}$. However, the overall size to obtain sieve size is important in determining exchangable Na reveals. The high $\mathrm{R}^{2}$ value was found to be 0.98 in validation $(\mathrm{RMSE}=0.07$ ) in the 0.250 mm mesh size.

\section{Conclusion}

Conventional analyses for soil chemical properties determination will likely remain the methods used by researchers in the near future. However, the use of portable and remote sensing tools for the determination of soil chemical contents may provided that require expensive and time-consuming analytical methods.

In conclusion, mesh sizes were not significant in prediction of lime, SOM, exchangable $\mathrm{Ca}+\mathrm{Mg}$ and the reflection values of the soil samples taken directly from field samplings can be used for prediction. However, mesh size were very important in prediction of CEC and exchangable $\mathrm{Na}$ and reflection values of soil samples taken in to $0.250 \mathrm{~mm}$ mesh size can be used for prediction.

\section{REFERENCES}

1. J.A.M. Demattê, R.C. Campos, M.C. Alves, P.R. Fiorio and M.R. Nanni, Geoderma, 121, 95 (2004).

2. R.A.V. Rossel, D.J.J. Walvoort, A.B. McBratney, L.J. Janik and J.O. Skjemstad, Geoderma, 131, 59 (2006).

3. C.W. Chang, D.A. Laird, M.J. Mausbach and C.R. Hurburgh, Soil Sci. Soc. Am. J., 65, 480 (2001).

4. B. Minasy, A.B. McBratney, G. Tranter and B.W. Murphy, Eur. J. Soil Sci., 59, 960 (2008).

5. L.J. Janik, R.H. Merry and J.O. Skjemstad, Australian J. Exp. Agric., 38, 681 (1998).

6. D.J. Brown, Geoderma, 140, 444 (2007).

7. D. Brunet, B.G. Barthès, J.L. Chotte and C Feller, Geoderma, 139, 106 (2007).

8. L. Kooistra, J. Wanders, G.F. Epema, R.S.E.W. Leuven, R. Wehrens and L.M.C. Buydens, Anal. Chim. Acta, 484, 189 (2003).

9. I. Bogrekci and W.S. Lee, Biosystems Eng., 92, 527 (2005). 
10. A.M. Mouazen, R. Karoui, J. De Baerdemaeker and H. Ramon, Soil Sci. Soc. Am. J., 70, 1295 (2006)

11. J.W. Hummel, K.A. Sudduth and S.E. Hollinger, Comp. Elec. Agric., 32, 149 (2001)

12. G. Fystro, Plant Soil, 246, 139 (2002).

13. R.C. Dalal and R.J. Henry, Soil Sci. Soc. Am. J., 50, 120 (1986).

14. J. Reeves III, G. McCarty and T. Mimmo, Environ. Pollut., 116, S277 (2002)

15. C.A. Russell, Com. Soil Sci. Plant Anal., 34, 1557 (2003)

16. M. Akgul, L. Basayigit, Y. Ucar and M. Mujdeci, The Soils of Atabey Plain, Suleyman Demirel University Agriculture Faculty of Publication No: 15, Research Series Edition No: 1, Isparta, Turkey (2001).

17. Soil Survey Staff: Soil Taxonomy, A Basic System of Soil Classification for Making and Interpreting Soil Surveys, Agriculture Handbook, edn. 2, Vol. 436, US Government Printing Office, DC., Washington, p. 869 (1999).

18. L.E. Allison and C.D. Moodie, in eds.: C.A. Black, Carbonate, Methods of Soil Analysis, Part 2, Agron. Monogr. 9, ASA, CSSA and SSSA, Madison, WI, edn. 2, pp. 1379-1400 (1965).
19. D.W. Nelson and L.E. Sommers, in ed.: A.L. Page, Total Carbon, Organic Carbon and Organic Matter, Methods of Soil Analysis, Part 2, Agron. Monogr. 9, ASA and SSSA, Madison, WI, edn. 2, pp. 539-579 (1982).

20. USDA: Diagnosis and Improvement of Saline and Alakli Soils, US Government Printing Office, Washington, DC, USA (1954).

21. M.T. Saglam, Soil Chemistry Notes Exercises, Ataturk University, Faculty of Agriculture, Department of Soil Science, (Unpublished) Erzurum, Turkey (1978).

22. H. Senol, M. Akgul, M. Mujdeci and L Basayigit, Afr. J. Agric. Res., 7, 2225 (2012).

23. L.K. Sørensen and S. Dalsgaard, Soil Sci. Soc. Am. J., 69, 159 (2005).

24. E. Ben-Dor and A. Banin, Soil Sci. Soc. Am. J., 59, 364 (1995).

25. L.J. Janik and J.O. Skjemstad, Australian J. Soil Res., 33, 637 (1995).

26. K.W. Daniel, N.K. Tripathi, K. Honda and E. Apisit, Int. J. Rem. Sen., 25, 643 (2004).

27. C.W. Chang, D.A. Laird and C.R. Hurburgh, Soil Sci., 170, 244 (2005).

28. K. Islam, B. Singh and A.B. McBratney, Australian J. Soil Res., 41, 1101 (2003).

29. K.D. Shepherd and M.G. Walsh, Soil Sci. Soc. Am. J., 66, 988 (2002). 